\title{
Characteristics in Water Phantom of Epithermal Neutron Beam Produced by Double Layer Beam Shaping Assembly
}

\author{
Bilalodin $^{1,2^{\star}}$, Gede Bayu Suparta ${ }^{1}$, Arief Hermanto ${ }^{1}$, Dwi Satya Palupi ${ }^{1}$, and Yohannes Sardjono ${ }^{3}$ \\ ${ }^{1}$ Department of Physics, Faculty of Mathematics and Natural Sciences, Universitas Gadjah Mada, Yogyakarta 55281, Indonesia \\ ${ }^{2}$ Department of Physics, Faculty of Mathematics and Natural Sciences, Jenderal Soedirman University, Purwokerto 53122, Indonesia \\ ${ }^{3}$ Center of Accelerator Science and Technology, National Nuclear Energy Agency, Yogyakarta 55281, Indonesia \\ ${ }^{*}$ Corresponding author: bilalodin.unsoed@gmail.com
}

KEYWORDS

Absorbed dose

DLBSA

Epithermal neutron \&

gamma distribution

Water phantom

\begin{abstract}
A double layer beam shaping assembly (DLBSA) was designed to produce epithermal neutrons for BNCT purposes. The Monte Carlo N-Particle eXtended program was used as the software to design the DLBSA and phantom. Distribution of epithermal neutron and gamma flux in the DLBSA and phantom and absorbed dose in the phantom were computed using the Particle and Heavy lon Transport code System program. Testing results of epithermal neutron beam irradiation of the water phantom showed that epithermal neutrons were thermalized and penetrated the phantom up to a depth of 12 $\mathrm{cm}$. The maximum value of the absorbed dose was $2 \times 10^{-3} \mathrm{~Gy}$ at a depth of $2 \mathrm{~cm}$ in the phantom.
\end{abstract}

(c) The Author(s) 2019. This article is distributed under a Creative Commons Attribution-ShareAlike 4.0 International license.

\section{INTRODUCTION}

Boron neutron capture therapy (BNCT) is a method in cancer therapy that causes minimal damage to normal tissues. This method makes use of the ability of boron to capture the neutron beam, subsequently killing cancer cells (Sauerwein et al. 2012).

In BNCT, highly lethal energetic particles $\left(\alpha,{ }^{7} \mathrm{Li}\right)$ produced after a breakup process of ${ }^{11} \mathrm{~B}$ nuclei when ${ }^{10} \mathrm{~B}$ atom captures a thermal neutron are used. The decay process of the boron-neutron reaction is shown in Equation 1 (Moghaddasi and Bezak 2018):

$$
\begin{aligned}
& { }^{1} n+{ }^{10} \mathrm{~B} \rightarrow{ }^{11} \mathrm{~B}+\gamma \\
& { }^{1} n+{ }^{10} \mathrm{~B} \rightarrow{ }^{7} \mathrm{Li}+{ }^{4} \mathrm{He}+\gamma \\
& { }^{1} n+{ }^{10} \mathrm{~B} \rightarrow{ }^{7} \mathrm{Li}+{ }^{4} \mathrm{He}
\end{aligned}
$$

The products of this reaction have high linear energy transfer characteristics $(\alpha$ particle approximately $150 \mathrm{keV}$ $\mathrm{\mu m}^{-1},{ }^{7} \mathrm{Li}$-nucleus approximately $\left.175 \mathrm{keV} \mathrm{mm}^{-1}\right)$. The path lengths of these particles in tissues are in the range of 4.5$10 \mathrm{\mu m}$ : hence resulting in an energy deposition limited to the diameter of a single cell.

Nuclear reactor neutron sources have long been used for BNCT, because high intensity neutron beams have been supplied only by reactors. However, many of these reactors have been shut down, reducing the number of reactors available for BNCT. Many reactors have been constructed only recently for BNCT. Conversely, accelerator-based neutron sources are becoming popular in neutron application fields (Kiyanagi 2018). Accelerators have several potential advantages related to safety, cost, and high neutron flux in the keV range, compared with reactor-based neutron sources for clinical radiotherapy (Peng et al. 2019).
One of accelerators used in BNCT comes from a cyclotron (Hashimoto et al. 2014). The resulting neutrons from the cyclotron are regulated so as to comply with the requirement set by the International Atomic Energy Agency (IAEA). Based on these criteria, the minimum beam intensity of the epithermal neutrons $(1 \mathrm{eV}<\mathrm{E}<10 \mathrm{keV})$ should be $5 \times 10^{8} \mathrm{n} / \mathrm{cm}^{2} . \mathrm{s}$, the number for fast neutron $(\mathrm{E}>10 \mathrm{keV})$ dose rate per epithermal neutrons flux and gamma dose rate per epithermal neutron flux should be less than $2 \times$ $10^{-13} \mathrm{~Gy} \mathrm{~cm}^{2}$ and the minimum number for the ratio of the epithermal neutrons flux to the thermal neutrons $(\mathrm{E}<1 \mathrm{eV})$ flux should be 100 (Ganjeh and Eslami-Kalantari 2019). The part of the cyclotron that is capable of processing the neutron beam is a beam shaping assembly (BSA).

Until now, most efforts for cyclotron-based BNCT have been focused on the design of the BSA to investigate the feasibility of clinical neutron beams having the desired characteristics for patient irradiation. To achieve this, many types of BSA have been designed using Monte Carlo N-Particle Transport Code (MCNP) and the Particle and Heavy Ion Transport code System (PHITS) program (Pelowitz 2008; Sato et al. 2013). The design is expected to produce neutrons that meet the IAEA standard of quality.

BSA designs used in neutron sources typically consist of the moderator, filter, reflector, and collimator as their main components (Kasesaz et al. 2014). Each of the components is commonly designed with a single layer configuration, i.e. they only use one type of material. Such a single-layer configuration has a weakness in that the components of BSA are not maximal in processing neutron radiation beams; hence the result is normally not optimal. To overcome this weakness, double layer and even multilayer configurations have been developed. Such configurations are yet to be optimized, to obtain better radiation beams, and tested, to find if the characteristics of the resulting 
beams meet the requirements for BNCT (Monshizadeh et al. 2015; Tanaka et al. 2011; Kasesaz et al. 2013).

In principle there are two ways to find the quality of beams for BNCT, either by assessing their quality in the air or in a water phantom. Assessment of radiation beams in the air complies with the IAEA standard (International Atomic Energy Agency 2001). As for the assessment in a water phantom, the emphasis is on the ability of radiation beams to penetrate the phantom and the dose of neutron sustained by a tumor (Ghal-Eh et al. 2017). A water phantom is typically chosen as the testing material because $70 \%$ of the human body consists of water (Tsukamoto et al. 2011). This article reports the characteristics of neutron and gamma distribution in a DLBSA and phantom, as well as the absorbed dose in a water phantom.

\section{MATERIALS AND METHODS}

The proton source was modeled as $30 \mathrm{MeV}$ protons impinging on ${ }^{9} \mathrm{Be}$ target with a diameter and thickness of 5 $\mathrm{cm}$ and $0.5 \mathrm{~cm}$, respectively. High-energy neutrons are supposed to originate from ${ }^{9} \mathrm{Be}(\mathrm{p}, \mathrm{n})$ reactions (Hashimoto et al. 2014). They are subsequently processed using a double layer beam shaping assembly (DLBSA) to yield epithermal neutrons. The configuration of the intended DLBSA is shown in Figure 1, and a three-dimensional model is shown in Figure 2.

The materials used as the moderator in the design of DLBSA were aluminum (Al) and LiF. The reason for the selection of $\mathrm{Al}$ was because of its high scattering cross-section. Aluminum has a high cross-section at energies above $10 \mathrm{keV}$ (Zaidi et al. 2017).

The materials used as reflectors were $\mathrm{Pb}$ and $\mathrm{FeC}$, which have a high density and ability to scatter fast neutron extremely well (Sato et al. 2013). Graphite (C) was also used as a reflector for its low cost. Apart from being cheap it also has a high scattering cross-section and low absorption, particularly at energies above $1 \mathrm{MeV}$ (Türkmen et al. 2017).

The collimator component under consideration was made of $\mathrm{Ni}$ and borated polyethylene materials. Ni is considered to be a stable element when it interacts with neutrons.

For a fast neutron filter, Fe was used. The effectiveness of Fe as a high energy neutron filter owes to its ability to inelastically scatter high energy neutrons passing through it. Fe is deemed to be superior in filtering fast neutrons. The ability of Fe to filter fast neutrons derives from its resonant cross-section, which is above $10 \mathrm{keV}$ (Asnal et al. 2015).

Thermal neutrons are filtered using a material with a high atomic number. Among the atoms with a high thermal neutron absorption cross-section is $\mathrm{Cd}$. Cd is frequently used as a thermal neutron filter. A cross-section of 20,600 barn is reasonably effective to absorb thermal neutrons (Osawa et al. 2017; Asnal et al. 2015).

The material used for shielding was $\mathrm{Pb}$. It has a relatively constant attenuation coefficient, i.e. $0.05 \mathrm{~cm}^{2} / \mathrm{g}$ to be able to absorb gamma rays with energies of $1-10 \mathrm{MeV}$ (Türkmen et al. 2017).

Epithermal neutrons leaving the DLBSA were subsequently imposed on the water phantom, shaped as a round ball, which was placed $1 \mathrm{~cm}$ at the front of the DLBSA. The composition of the water phantom in this study was $11.2 \%$ of $\mathrm{H}$ atoms and $88.8 \%$ of $\mathrm{O}$ atoms, with a density of 1000 $\mathrm{kg} / \mathrm{cm}^{3}$ (Raaijmakers et al. 2000).

Monte Carlo simulation was carried out using the MCNPX and PHITS programs. The MNCPX program was used

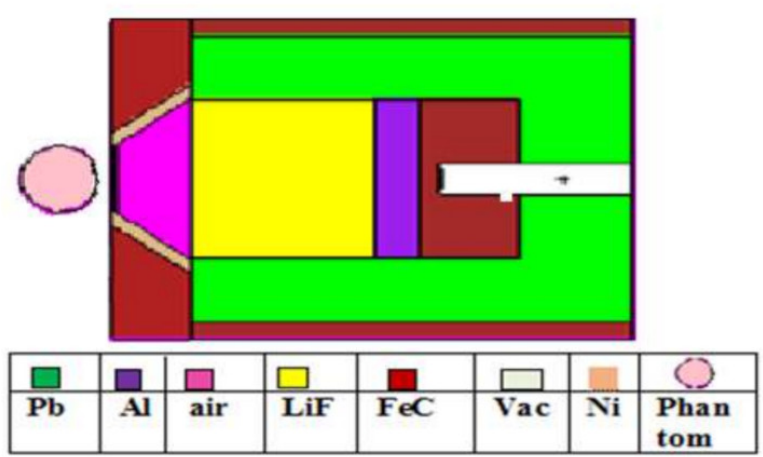

FIGURE 1. Configuration of DLBSA and water phantom.

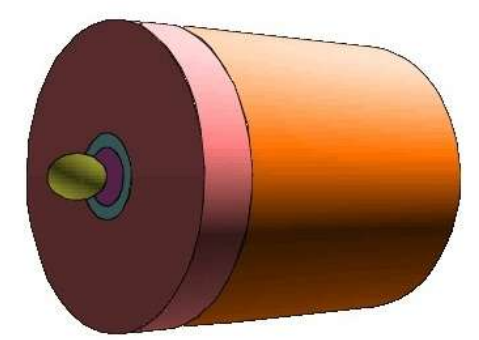

FIGURE 2. Three-dimensional model of DLBSA and water phantom.

as the software to design the DLBSA and phantom (Pelowitz 2008). The distributions of epithermal neutron and gamma flux in the DLBSA and phantom and neutron absorbed dose in the phantom were computed using the PHITS program (Sato et al. 2013). The track and deposit tally were used in the PHITS calculation. To draw the particle track and visualization geometry of DLBSA, the ANGEL software was used. The transport was based on the cross-section data library JENDL-4.0 for neutrons and photons, and intra-nuclear cascade (INCL4.6) for protons.

\section{RESULTS AND DISCUSSION}

\subsection{Characteristics of neutron and gamma beams in DLBSA and water phantom}

Figure 3 shows the distribution of epithermal neutrons in the DLBSA. The fast neutrons mainly resulted from reactions of $30 \mathrm{MeV}$ protons with ${ }^{9} \mathrm{Be}$ target material through ${ }_{4}^{9} \mathrm{Be}(p, n){ }_{5}^{9} \mathrm{~B}$. Fast neutrons interacted with $\mathrm{Al}$ and $\mathrm{LiF}$ moderator, producing epithermal neutrons. The flux of epithermal neutrons around the moderator and filter reached $10^{11}$ $\mathrm{n} / \mathrm{cm}^{2} . \mathrm{s}$. The increase in the amount of epithermal neutrons was also sustained by the presence of Fe placed in front of the moderator filtering high energy neutrons. The effectiveness of Fe as a filter for high energy neutrons is due to its ability to inelastically scatter high energy neutrons passing through the Fe material (Asnal et al. 2015). The flux of epithermal neutrons computed at the end of the collimator exceeded $10^{9} \mathrm{n} / \mathrm{cm}^{2} . \mathrm{s}$.

An epithermal neutron flux entering the phantom continually decreases in energy (as reflected in the change in color from yellow to blue in the phantom). The decrease in epithermal neutron flux is due to epithermal neutrons transforming into thermal neutrons during interactions with hydrogen atoms. This process is called thermalization (Mishima 1996). The neutron flux in the phantom decreased from $10^{9} \mathrm{n} / \mathrm{cm}^{2}$.s to $10^{6} \mathrm{n} / \mathrm{cm}^{2} . \mathrm{s}$. 


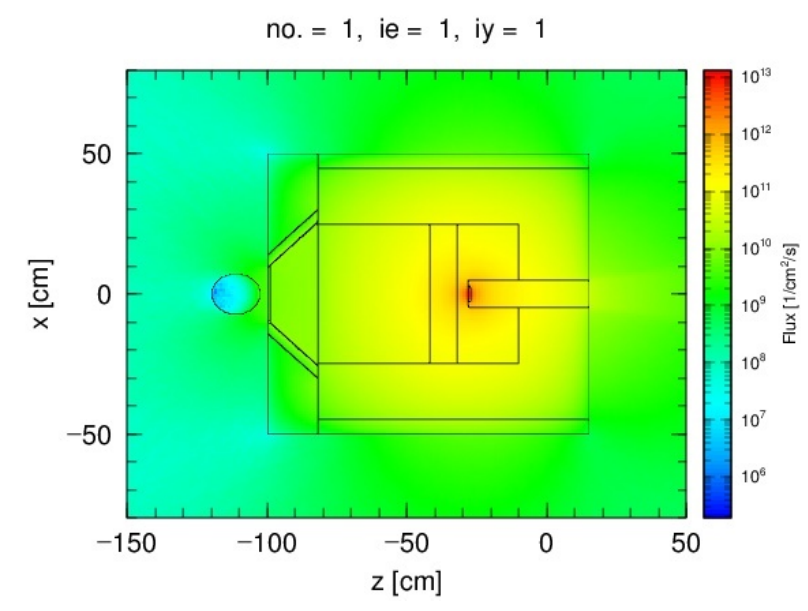

FIGURE 3. Distribution of epithermal neutron flux in DLBSA and water phantom.

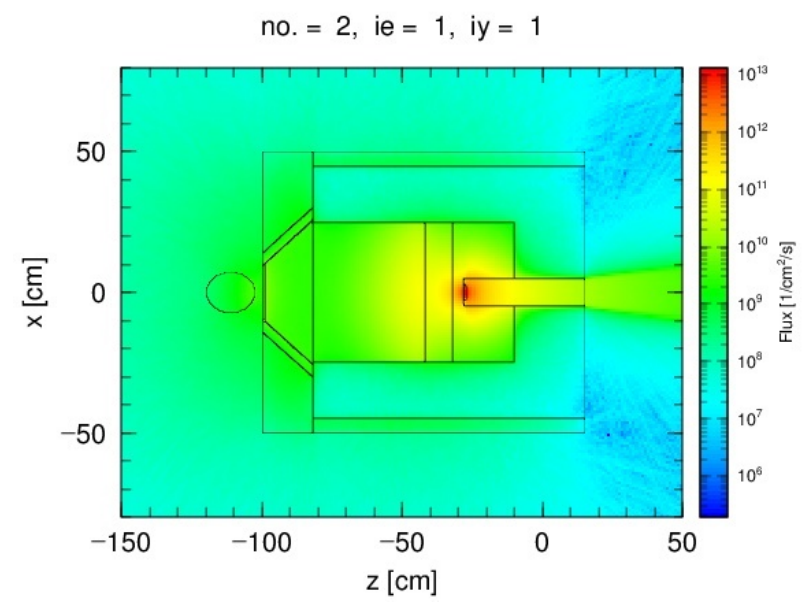

FIGURE 4. Distribution of gamma in DLBSA and water phantom.

Figure 4 shows the distribution of gamma particles in the DLBSA and water phantom. The gamma particle flux around the beryllium target was $10^{12} \mathrm{\gamma} / \mathrm{s}^{\mathrm{cm}} \mathrm{cm}^{2}$. The particles were dominantly produced from interactions of protons with a beryllium target through ${ }_{4}^{9} B e(p, \alpha){ }_{3}^{6} L i^{*}(\gamma){ }_{3}^{6} L i$ reactions. A small fraction of gamma rays was also generated from capture reactions through ${ }_{4}^{9} \mathrm{Be}(p, \gamma){ }_{4}^{10} \mathrm{Be}$ reactions and inelastic collision mechanisms in the form of ${ }_{4}^{9} B e\left(n, n^{\prime} \gamma\right)$ reaction (Hu et al. 2016). Gamma particles were produced from the reaction of neutrons with aluminum through ${ }^{27} A l(n, \gamma)^{28} A l$ reactions (Ma et al. 2015). Gamma particles enter the phantom and interact with $\mathrm{H}$ and $\mathrm{O}$, losing their energy through mechanisms of photoelectric effect, Compton scattering, and pair production (Lamarsh and Baratta 2001). These interactions cause gamma ray flux to continually decline in the phantom.

\subsection{Neutron absorbed dose in water phantom}

Figure 5 shows the neutron absorbed dose in the water phantom, the maximum value of which was $2 \times 10^{-3} \mathrm{~Gy}$, obtained at a depth of $2 \mathrm{~cm}$ from the surface of the phantom. This value is in accordance with the work of Tanaka et al. (2011) and Morcos and Naguib (2012). The deeper the epithermal neutron penetrates the phantom, the greater the increase in thermalization, causing the value of neutron flux to diminish. The decrease in neutron flux is caused by the thermalization of neutrons with H (Mishima 1996).

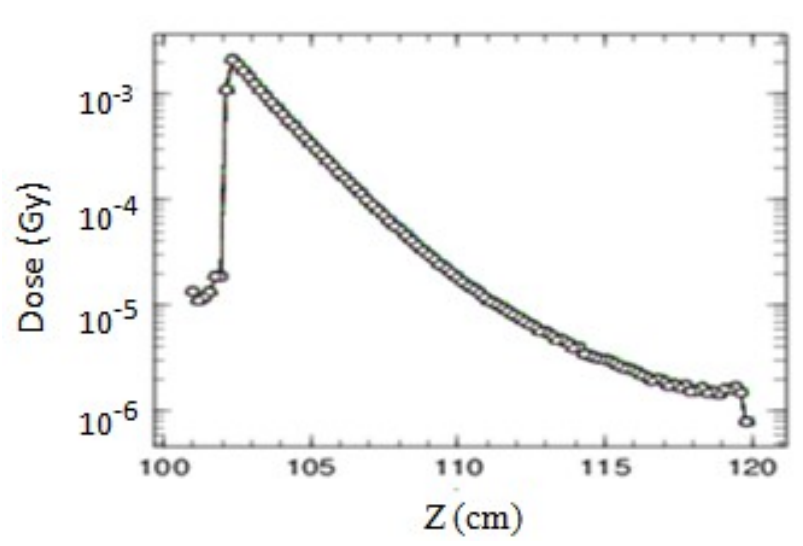

FIGURE 5. Neutron absorbed dose characteristic in water phantom.

Based on the neutron characteristics in the phantom, the neutron beams produced by the DLBSA can be considered as a neutron source for BNCT. The ability of epithermal neutrons in a phantom shows that the neutron beams from the DLBSA can be utilized as a neutron source for the treatment of cancerous tumors situated at $2-8 \mathrm{~cm}$. Some of the types of cancers that can be treated using such a neutron source are head and neck cancer, glioblastoma, lung cancer, breast cancer, pancreatic cancer, brain tumors and sarcoma (Moss 2014; Mirzaei et al. 2016).

\section{CONCLUSIONS}

A double layer beam shaping assembly was designed to produce epithermal neutrons for BNCT purposes. The results of modeling of the DLBSA and phantom show that the distribution of epithermal neutrons in the DLBSA and phantom continually decrease in neutron and gamma flux. The decrease in epithermal neutron flux and gamma is due to the thermalization process. Epithermal neutrons penetrated the phantom up to $12 \mathrm{~cm}$ in depth. Meanwhile, the maximum neutron absorbed dose in the phantom was found at a depth of $2 \mathrm{~cm}$, with $2 \times 10^{-3}$ Gy in value. These results show that the neutron beams produced by the DLBSA are adequate as a neutron source for BNCT, particularly in the treatment of deep-seated tumors.

\section{ACKNOWLEDGMENTS}

The authors would like to thank the Ministry of Research, Technology and Higher Education of the Republic of Indonesia for its BPPDN Scholarship and Doctoral Dissertation Research Grant, as well as BATAN for its consent to the use of the MCNPX and PHITS code. We are also thankful to the late Prof. Dr. Kusminarto for his support in the conducting of this research.

\section{REFERENCES}

Asnal M, Liamsuwan T, Onjun T. 2015. An evaluation on the design of beam shaping assembly based on the D$\mathrm{T}$ reaction for BNCT. J Phys Conf Ser. 611:012031. doi: 10.1088/1742-6596/611/1/012031.

Ganjeh ZA, Eslami-Kalantari M. 2019. Design and optimization of two-sided beam based on ${ }^{7} \mathrm{Li}(\mathrm{p}, \mathrm{n})^{7}$ Be source using in BNCT for brain and liver tumors. Nucl Instrum Methods Phys Res A. 916:290-295. doi:10.1016/j.nima.2 018.11.084.

Ghal-Eh N, Goudarzi H, Rahmani F. 2017. FLUKA simulation studies on in-phantom dosimetric parameters of 
a LINAC-based BNCT. Radiat Phys Chem. 141:36-40. doi:10.1016/j.radphyschem.2017.06.004.

Hashimoto Y, Hiraga F, Kiyanagi Y. 2014. Effects of proton energy on optimal moderator system and neutroninduced radioactivity of compact accelerator-driven ${ }^{9} \mathrm{Be}(\mathrm{p}, \mathrm{n})$ neutron sources for BNCT. Phys Procedia. 60:332-340. doi:10.1016/J.PHPRO.2014.11.045.

Hu G, Hu HS, Wang S, Pan ZH, Jia QG, Yan MF. 2016. The "neutron channel design"-a method for gaining the desired neutrons. AIP Adv. 6(12):125025. doi:10.1063/1.49 72203.

International Atomic Energy Agency. 2001. Current status of neutron capture therapy. Number 1223 in TECDOC Series. Vienna: International Atomic Energy Agency. ht tps://www.iaea.org/publications/6168/current-sta tus-of-neutron-capture-therapy.

Kasesaz Y, Khalafi H, Rahmani F. 2013. Optimization of the beam shaping assembly in the D-D neutron generatorsbased BNCT using the response matrix method. Appl Radiat Isot. 82:55-59. doi:10.1016/j.apradiso.2013.07.0 08.

Kasesaz Y, Khalafi H, Rahmani F. 2014. Design of an epithermal neutron beam for BNCT in thermal column of Tehran research reactor. Ann Nucl Energy. 68:234-238. doi:10.1016/J.ANUCENE.2014.01.014.

Kiyanagi Y. 2018. Accelerator-based neutron source for boron neutron capture therapy. Ther Radiol Oncol. 2:55-55. doi:10.21037/tro.2018.10.05.

Lamarsh JR, Baratta AJ. 2001. Introduction to nuclear engineering. 3rd edition. New Jersey: Prentice Hall.

Ma CW, Lv CJ, Zhang GQ, Wang HW, Zuo JX. 2015. Neutroninduced reactions on $\mathrm{AlF}_{3}$ studied using the optical model. Nucl Instrum Methods Phys Res B. 356-357:4245. doi:10.1016/J.NIMB.2015.04.060.

Mirzaei H, Sahebkar A, Salehi R, Nahand J, Karimi E, Jaafari M, Mirzaei H. 2016. Boron neutron capture therapy: Moving toward targeted cancer therapy. J Cancer Res Ther. 12(2):520. doi:10.4103/0973-1482.176167.

Mishima Y.1996. Selective thermal neutron capture therapy of cancer cells using their specific metabolic activitiesmelanoma as prototype. In: Mishima Y, editor. Cancer neutron capture therapy. Boston: Springer. p. 1-26. doi: 10.1007/978-1-4757-9567-7_1.

Moghaddasi L, Bezak E. 2018. Geant4 beam model for boron neutron capture therapy: investigation of neutron dose components. Australas Phys Eng Sci Med. 41(1):129-141. doi:10.1007/s13246-018-0617-z.

Monshizadeh M, Kasesaz Y, Khalafi H, Hamidi S. 2015. MCNP design of thermal and epithermal neutron beam for BNCT at the Isfahan MNSR. Prog Nucl Energy. 83:427-432. doi:10.1016/J.PNUCENE.2015.05.004.

Morcos HN, Naguib K. 2012. QMENF-G: a computer pack- age for quasi-mono-energetic neutron filters. Ann Nucl Energy. 40(1):237-240. doi:10.1016/j.anucene.2011 .09.020.

Moss RL. 2014. Critical review, with an optimistic outlook, on boron neutron capture therapy (BNCT). Appl Radiat Isot. 88:2-11. doi:10.1016/J.APRADISO.2013.11.109.

Osawa Y, Imoto S, Kusaka S, Sato F, Tanoshita M, Murata I. 2017. Development of an epi-thermal neutron field for fundamental researches for BNCT with a DT neutron source. EPJ Web Conf. 153:04008. doi:10.1051/epjcon f/201715304008.

Pelowitz DB, editor. 2008. MCNPX user's manual. New Mexico: Los Alamos National Library.

Peng M, He GZ, Zhang QW, Shi B, Tang HQ, Zhou ZY. 2019. Study of neutron production and moderation for sulfur neutron capture therapy. Nucl Sci Tech. 30(1):2. doi: 10.1007/s41365-018-0529-3.

Raaijmakers CPJ, Nottelman EL, Mijnheer BJ, Nottelman EL. 2000. Phantom materials for boron neutron capture therapy. Phys Med Biol. 45(8):2353-2361. doi:10.1088/ 0031-9155/45/8/320.

Sato T, Niita K, Matsuda N, Hashimoto S, Iwamoto Y, Noda S, Ogawa T, Iwase H, Nakashima H, Fukahori T, Okumura K, Kai T, Chiba S, Furuta T, Sihver L. 2013. Particle and Heavy Ion Transport code System, PHITS, version 2.52. J Nucl Sci Technol. 50(9):913-923. doi:10.1080/002231 31.2013.814553.

Sauerwein W, Wittig A, Moss R, Nakagawa Y, editors. 2012. Neutron capture therapy: principles and applications. Berlin: Springer. doi:10.1007/978-3-642-31334-9.

Tanaka H, Sakurai Y, Suzuki M, Masunaga S, Mitsumoto T, Fujita K, Kashino G, Kinashi Y, Liu Y, Takada M, Ono K, Maruhashi A. 2011. Experimental verification of beam characteristics for cyclotron-based epithermal neutron source (C-BENS). Appl Radiat Isot. 69(12):16421645. doi:10.1016/J.APRADISO.2011.03.020.

Tsukamoto $\mathrm{T}$, Tanaka $\mathrm{H}$, Yoshinaga $\mathrm{H}$, Mitsumoto $\mathrm{T}$, Maruhashi A, Ono K, Sakurai Y. 2011. A phantom experiment for the evaluation of whole body exposure during BNCT using cyclotron-based epithermal neutron source (C-BENS). Appl Radiat Isot. 69(12):1830-1833. doi:10.1016/J.APRADISO.2011.03.013.

Türkmen M, Ergün Ş, Çolak Ü. 2017. A new method in beam shaping: Multi-Objective Genetic Algorithm method coupled with a Monte-Carlo based reactor physics code. Prog Nucl Energy. 99:165-176. doi:10.1016/J.PN UCENE.2017.05.008.

Zaidi L, Kashaeva EA, Lezhnin SI, Malyshkin GN, Samarin SI, Sycheva TV, Taskaev SY, Frolov SA. 2017. Neutronbeam-shaping assembly for boron neutron-capture therapy. Phys At Nucl. 80(1):60-66. doi:10.1134/S10637 7881701015X 